\title{
Cardiopulmonary exercise capacity and limitations 3 months after COVID-19 hospitalisation
}

\author{
Ingunn Skjørten ${ }^{1}$, Odd Andre Wathne Ankerstjerne ${ }^{1}$, Divna Trebinjac ${ }^{1}$, Eivind Brønstad ${ }^{2,3}$, \\ Øystein Rasch-Halvorsen ${ }^{2,3}$, Gunnar Einvik ${ }^{4,5}$, Tøri Vigeland Lerum ${ }^{6}$, Knut Stavem $\mathbb{1}^{4,5,7}$, \\ Anne Edvardsen ${ }^{4}$ and Charlotte Björk Ingul ${ }^{1,2,8}$
}

${ }^{1}$ LHL Hospital Gardermoen, Jessheim, Norway. ${ }^{2}$ Dept of Circulation and Medical Imaging, Norwegian University of Science and Technology, Trondheim, Norway. ${ }^{3}$ Thoracic Dept, St Olavs University Hospital, Trondheim, Norway. ${ }^{4}$ Pulmonary Dept, Akershus University Hospital, Lørenskog, Norway. ${ }^{5}$ Institute for Clinical Medicine, University of Oslo, Oslo, Norway. ${ }^{6}$ Dept of Pulmonary Medicine, Oslo University Hospital Ullevål, Oslo, Norway. ${ }^{7}$ Health Services Research Unit, Akershus University Hospital, Lørenskog, Norway. ${ }^{8}$ Faculty of Nursing and Health Sciences, Nord University, Bodø, Norway.

Corresponding author: Charlotte Björk Ingul (charlotte.b.ingul@ntnu.no)

Shareable abstract (@ERSpublications)

Oxygen uptake was reduced in one-third of participants 3 months after hospitalisation for COVID19. The most common exercise limitation was deconditioning. Circulatory limitations to exercise were more common than ventilatory limitations. https://bit.ly/3jmVDQ6

Cite this article as: Skjørten I, Ankerstjerne OAW, Trebinjac D, et al. Cardiopulmonary exercise capacity and limitations 3 months after COVID-19 hospitalisation. Eur Respir J 2021; 58: 2100996 [DOI: 10.1183/ 13993003.00996-2021].

Copyright (The authors 2021

This version is distributed under the terms of the Creative Commons Attribution NonCommercial Licence 4.0. For commercial reproduction rights and permissions contact permissions@ersnet.org

This article has an editorial commentary: https://doi.org/10.1183/ 13993003.01763-2021

Received: 5 April 2021 Accepted: 21 June 2021

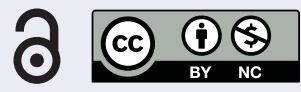

\section{Abstract}

Background This study aimed to describe cardiopulmonary function during exercise 3 months after hospital discharge for COVID-19 and compare groups according to dyspnoea and intensive care unit (ICU) stay.

Methods Participants with COVID-19 discharged from five large Norwegian hospitals were consecutively invited to a multicentre, prospective cohort study. In total, 156 participants (mean age 56.2 years, 60 females) were examined with a cardiopulmonary exercise test (CPET) 3 months after discharge and compared with a reference population. Dyspnoea was assessed using the modified Medical Research Council (mMRC) dyspnoea scale.

Results Peak oxygen uptake $\left(V_{\mathrm{O}_{2} \text { peak }}^{\prime}\right)<80 \%$ predicted was observed in $31 \%(\mathrm{n}=49)$. Ventilatory efficiency was reduced in $15 \%(n=24)$, while breathing reserve $<15 \%$ was observed in $16 \%(n=25)$. Oxygen pulse $<80 \%$ predicted was found in $18 \%(n=28)$. Dyspnoea (mMRC $\geqslant 1$ ) was reported by $47 \%$ $(\mathrm{n}=59)$. These participants had similar $V_{\mathrm{O}_{2} \text { peak }}^{\prime}(\mathrm{p}=0.10)$ but lower mean $\pm \mathrm{SD} V_{\mathrm{O}_{2} \text { peak }}^{\prime} \cdot \mathrm{kg}^{-1} \%$ predicted compared with participants without dyspnoea (mMRC 0) $(76 \pm 16 \%$ versus $89 \pm 18 \%$; $\mathrm{p}=0.009)$ due to higher body mass index $(\mathrm{p}=0.03)$. For ICU- versus non-ICU-treated participants, mean $\pm \mathrm{SD} V_{\mathrm{O}_{2} \text { peak }} \%$ predicted was $82 \pm 15 \%$ and $90 \pm 17 \%(\mathrm{p}=0.004)$, respectively. Ventilation, breathing reserve and ventilatory efficiency were similar between the ICU and non-ICU groups.

Conclusions One-third of participants experienced $V_{\mathrm{O}_{2} \text { peak }}^{\prime}<80 \%$ predicted 3 months after hospital discharge for COVID-19. Dyspnoeic participants were characterised by lower exercise capacity due to obesity and lower ventilatory efficiency. Ventilation and ventilatory efficiency were similar between ICUand non-ICU-treated participants.

\section{Introduction}

Severe acute respiratory syndrome coronavirus 2 (SARS-CoV-2) is responsible for the COVID-19 pandemic [1, 2]. COVID-19 mainly affects the respiratory system, but other organs may also be involved [3]. A recent 6-month follow-up study found the most common persistent COVID-19 symptoms to be fatigue/muscle weakness (63\%) and dyspnoea (26\%) [4]. Several studies have reported a high prevalence of dyspnoea (16-89\%) at 1.5-6 months after COVID-19 in hospitalised and nonhospitalised participants [5-8]. 
A recent report from a Norwegian cohort of hospitalised COVID-19 patients found no strong association between dyspnoea at 3 months and reduced gas diffusion capacity [7], although close to one-fifth reported dyspnoea $>1$ on the modified Medical Research Council (mMRC) dyspnoea scale [7, 9]. A cardiopulmonary exercise test (CPET) might differentiate the pathophysiological mechanisms of reduced exercise capacity and dyspnoea [10], as it integrates assessments of the cardiovascular, respiratory and muscular systems during maximum exertion [11]. Two studies reporting CPET data for 81 participants after hospitalisation for moderate-to-severe COVID-19 found reduced peak oxygen uptake $\left(V^{\prime} \mathrm{O}_{2}\right.$ peak $)$ in a large proportion of participants [3,12]. One of the studies selectively included participants treated with mechanical ventilation and both studies included a limited number of participants. To the best of our knowledge, no multicentre, population-based study has yet reported extensive CPET results or compared different subgroups of hospitalised COVID-19 patients. We hypothesised that COVID-19 patients would have reduced exercise capacity. Furthermore, we hypothesised persistent cardiopulmonary exercise limitations, particularly in persons with self-reported dyspnoea or intensive care unit (ICU) admission. Therefore, we aimed to determine cardiopulmonary function during exercise 3-4 months after hospital discharge for COVID-19 compared with a reference population and to describe the characteristics of participants with exercise limitations.

\section{Methods}

\section{Study design and sample}

The current study is a substudy of Patient-Reported Outcomes and Lung Function after Hospital Admission for COVID-19 (PROLUN), a multicentre prospective cohort study performed at six hospitals in southern Norway [7]. The substudy included participants from five of the hospitals. Participants $\geqslant 18$ years who had been admitted for $>8 \mathrm{~h}$ with a discharge diagnosis of COVID-19 before 1 June 2020 were considered eligible. Exclusion criteria included prior diagnosis of chronic obstructive pulmonary disease (COPD), myocardial infarction, heart failure or peripheral arterial disease, living outside the hospitals' catchment areas, inability to provide informed consent, or participating in the World Health Organization (WHO) Solidarity trial. Further details on the study design and participants have been reported [7]. Eligible participants were invited by mail at 2-4 weeks after hospital discharge. Informed consent was obtained by returning a written signed consent form or through a secure digital consent form (Services for Sensitive Data (TSD), University of Oslo, Oslo, Norway). Among the 264 participants who provided consent for the main study, 236 were invited to participate in the current substudy. The participants were examined 3 months after hospital discharge. The WHO Ordinal Scale for Clinical Improvement was used to score the severity of COVID-19 infection [13].

PROLUN was approved by the Regional Ethics Committee of South-Eastern Norway (125384) and data protection officers at each participating centre, and was registered at ClinicalTrials.gov with identifier number NCT04535154.

\section{Pulmonary function tests}

Pulmonary function tests included spirometry and diffusing capacity of the lung for carbon monoxide $\left(D_{\text {LCO }}\right)$ (Jaeger Master Screen PFT; Vyaire Medical, Höchberg, Germany). International reference values were applied $[14,15]$. The mMRC dyspnoea scale was used as a self-rating tool to measure the degree of disability that breathlessness poses on activities of daily living on a scale from 0 to 4 [9]. Participants were categorised as having dyspnoea (mMRC 1-4) or no dyspnoea (mMRC 0).

\section{Cardiopulmonary exercise test}

The CPET (Jaeger Vyntus CPX; Vyaire Medical) was performed on a treadmill with continuous measurements of minute ventilation $\left(V_{\mathrm{E}}^{\prime}\right), V_{\mathrm{O}_{2}}^{\prime}$, carbon dioxide production $\left(V_{\mathrm{CO}_{2}}^{\prime}\right)$, heart rate, ECG and oxygen saturation measured by pulse oximetry $\left(S_{\mathrm{pO}_{2}}\right)[10,16]$. An incremental modified Bruce protocol to exhaustion was specified for each participant based on reported exercise tolerance. Concurrently, perceived exertion and dyspnoea were assessed using the Borg CR10 scale [17]. $V_{\mathrm{O}_{2}}^{\prime} \cdot \mathrm{kg}^{-1}$, oxygen pulse $\left(V_{\mathrm{O}_{2}}^{\prime} /\right.$ heart rate), $V_{E}^{\prime} / V_{\mathrm{CO}_{2}}^{\prime}$ slope and ventilatory equivalents were calculated. $V_{\mathrm{O}_{2}}^{\prime} \cdot \mathrm{kg}^{-1}$ will be referred to as exercise capacity. Ventilatory efficiency was assessed by the $V_{\mathrm{E}}^{\prime} / V^{\prime} \mathrm{CO}_{2}$ slope up to the ventilatory compensation point and by nadir ventilatory equivalent for carbon dioxide $\left(V_{\mathrm{E}}^{\prime} / V_{\mathrm{CO}_{2} \text { nadir }}^{\prime}\right)$. Breathing reserve was calculated as $\left(1-V_{\text {Epeak }}^{\prime} /\right.$ maximal voluntary ventilation $\left.(\mathrm{MVV})\right) \times 100 \%$, using an estimate of forced expiratory volume in $1 \mathrm{~s}\left(\mathrm{FEV}_{1}\right) \times 40$ for MVV [10]. The anaerobic threshold was assessed by the V-slope method [16]. A capillary blood sample was drawn from the fingertip immediately after exercise termination and analysed for lactate, $\mathrm{pH}$ and carbon dioxide tension (ABL 800 Flex; Radiometer Medical, Copenhagen, Denmark). All CPETs were performed at two test centres: LHL Hospital Gardermoen (Jessheim, Norway) or St Olavs University Hospital (Trondheim, Norway). 
Interpretation of the CPET

Normal values from a Norwegian reference population with similar comorbidities (hypertension and diabetes) were used to compare the participants' cardiopulmonary function during exercise [18]. z-scores $\leqslant 1.96$ were defined as abnormally reduced and z-scores $>1.96$ as abnormally increased, corresponding to the 2.5th and 97.5th percentiles of the reference population [14, 19]. To allow comparisons with other published studies, some of the CPET variables were reported as $<80 \%$ of the predicted value.

The cause of limitation to exercise was determined for all participants with $V_{\mathrm{O}_{2} \text { peak }}^{\prime}<80 \%$ predicted. Ventilatory limitation to exercise was considered when breathing reserve was $<15 \%$. Circulatory limitation was considered when the Wassermann flowchart led to a circulatory category [16], including ECG changes consistent with ischaemia or arrhythmia. Ischaemia was defined as $\geqslant 1 \mathrm{~mm}$ horizontal or downsloping ST segment depression in at least two adjacent leads that persisted at $80 \mathrm{~ms}$ after the $\mathrm{J}$ point. Deconditioning was considered in participants with $V_{\mathrm{O}_{2} \text { peak }}^{\prime}<80 \%$ predicted without evidence of ventilatory or circulatory exercise limitations. For the consideration of dysfunctional breathing as a reason for high $V_{\mathrm{E}}^{\prime} / V^{\prime} \mathrm{CO}_{2}$ nadir and $V^{\prime}{ }_{E} / V^{\prime} \mathrm{CO}_{2}$ slope, visual inspection of changes in tidal volume and respiratory frequency during exercise was made, as well as evaluation of capillary carbon dioxide tension and $\mathrm{pH}$ at peak exercise.

\section{Biochemistry}

Nonfasting venous blood samples were collected to measure haemoglobin, C-reactive protein, N-terminal pro-brain natriuretic peptide (Cobas 8000, e801, e601; Roche Diagnostics, Mannheim, Germany and Architect i2000SR; Abbott, Chicago, IL, USA) and high-sensitivity cardiac troponin T (Cobas 8000, e801, e601). The maximum values during hospital stay and after 3 months are reported.

\section{Statistical analyses}

Descriptive statistics are presented as mean with standard deviation, median (interquartile range (IQR)) or number (percentage), as appropriate. z-scores were compared with 0 using the Wilcoxon signed-rank test. Group comparisons of dyspnoea versus no dyspnoea and ICU versus non-ICU were performed with linear regression analysis for continuous variables, adjusting for age and sex. Because of the slight deviation from a normal distribution of the residuals in some of the linear regression models, we estimated p-values from bootstrapping with 10000 repetitions for all models. All statistical analyses were performed using Stata version 16.1 (StataCorp, College Station, TX, USA). We chose a 5\% significance level using two-sided tests.

\section{Results}

\section{Participant characteristics and initial treatment}

Of the 236 participants invited from the main study, 189 consented to participate in the present substudy, which was completed at a median (IQR) of 104 (90-139) days after discharge from the hospital. 26 participants were excluded due to comorbidity (COPD, myocardial infarction, heart failure or peripheral arterial disease) and seven had a submaximal, inconclusive CPET (figure 1). Table 1 summarises the

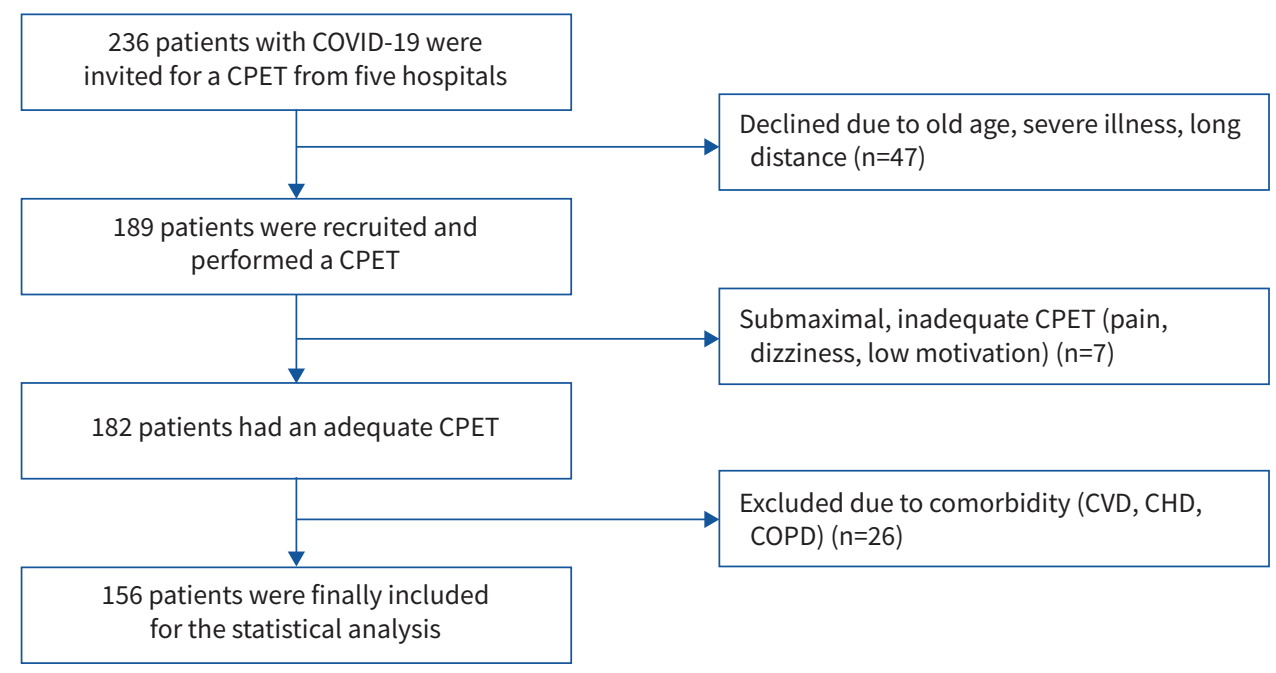

FIGURE 1 Patient flowchart. CPET: cardiopulmonary exercise test; CVD: cardiovascular disease; CHD: coronary heart disease: COPD: chronic obstructive pulmonary disease. 
TABLE 1 Descriptive statistics for 156 COVID-19 patients

\begin{tabular}{|c|c|c|c|}
\hline & $\mathrm{n}$ or $\mathrm{n}(\%)$ & Mean \pm SD & Median (IQR) \\
\hline Age at hospital discharge, years & 156 & $56.2 \pm 12.7$ & \\
\hline Female & $60(39)$ & & \\
\hline $\mathrm{BMI}, \mathrm{kg} \cdot \mathrm{m}^{-2}$ & 152 & $27.9 \pm 4.5$ & \\
\hline Smoking status & 141 & & \\
\hline Never smoked & $83(59)$ & & \\
\hline Formerly a daily smoker & $56(40)$ & & \\
\hline Current daily smoker & $2(1)$ & & \\
\hline Medical history & 156 & & \\
\hline CVA/TIA & $2(1)$ & & \\
\hline Hypertension & $46(31)$ & & \\
\hline Asthma & $25(16)$ & & \\
\hline Diabetes mellitus & $14(9)$ & & \\
\hline $\mathrm{P}-\mathrm{hsTnT} \mathrm{Tax}_{\max }$ during hospitalisation, $\mathrm{ng} \cdot \mathrm{L}^{-1}$ & 129 & & $8.0(5.5-15.5)$ \\
\hline Abnormal P-hsTnT $\max$ during hospitalisation & $14(9)$ & & \\
\hline P-hsTnT at 3 months, $n g \cdot L^{-1}$ & 139 & & $7.0(5.0-10.0)$ \\
\hline NT-proBNP $\max$ during hospitalisation, $\mathrm{ng} \cdot \mathrm{L}^{-1}$ & 132 & & $173(64-409)$ \\
\hline Abnormal NT-proBNP $_{\max }$ during hospitalisation & $60(39)$ & & \\
\hline NT-proBNP at 3 months, $\mathrm{ng} \cdot \mathrm{L}^{-1}$ & 148 & & $55(35-100)$ \\
\hline $\mathrm{Hb}$ during hospitalisation, $\mathrm{g} \cdot \mathrm{dL}^{-1}$ & 154 & & $14.2(13.3-15.0)$ \\
\hline $\mathrm{Hb}$ at 3 months, $\mathrm{g} \cdot \mathrm{dL}^{-1}$ & 148 & & $14.5(13.5-15.2)$ \\
\hline $\mathrm{CRP}_{\max }$ during hospitalisation, $\mathrm{mg} \cdot \mathrm{L}^{-1}$ & 153 & & $110(37-205)$ \\
\hline Time from symptom start to PFT, days & 150 & $113 \pm 30$ & \\
\hline \multicolumn{4}{|l|}{ Spirometry and body plethysmography } \\
\hline FVC, L & 152 & $4.0 \pm 1.0$ & \\
\hline FVC, \% pred & 152 & $96 \pm 14$ & \\
\hline $\mathrm{FEV}_{1}, \mathrm{~L}$ & 152 & $3.1 \pm 0.8$ & \\
\hline $\mathrm{FEV}_{1}, \%$ pred & 152 & $95 \pm 15$ & \\
\hline $\mathrm{FEV}_{1} / \mathrm{FVC}$ & 152 & $0.78 \pm 0.07$ & \\
\hline TLC, \% pred & 140 & $94 \pm 16$ & \\
\hline Residual volume, \% pred & 140 & $95 \pm 28$ & \\
\hline \multicolumn{4}{|l|}{ Gas diffusion } \\
\hline$D_{\mathrm{LCO}}, \mathrm{mmol} \cdot \mathrm{kPa}^{-1} \cdot \mathrm{min}^{-1}$ & 153 & $7.6 \pm 2.1$ & \\
\hline$D_{\text {Lco }} \%$ pred & 153 & $84 \pm 16$ & \\
\hline$D_{\mathrm{LCO}} / V_{\mathrm{A}}, \mathrm{mmol} \cdot \mathrm{kPa}^{-1} \cdot \mathrm{min}^{-1} \cdot \mathrm{L}^{-1}$ & 153 & $1.4 \pm 0.3$ & \\
\hline$D_{\mathrm{LCO}} / V_{\mathrm{A}}, \%$ pred & 153 & $97 \pm 18$ & \\
\hline mMRC dyspnoea scale & 126 & & \\
\hline 0 & $67(53)$ & & \\
\hline 1 & $35(28)$ & & \\
\hline 2 & $17(14)$ & & \\
\hline 3 & $5(4)$ & & \\
\hline 4 & $2(2)$ & & \\
\hline \multicolumn{4}{|l|}{ WHO Ordinal Scale for Clinical Improvement } \\
\hline 3 & $60(39)$ & & \\
\hline 4 & $68(44)$ & & \\
\hline $5-7$ & $27(17)$ & & \\
\hline
\end{tabular}

IQR: interquartile range; BMI: body mass index; CVA: cerebral vascular accident; TIA: transient ischaemic attack; P-hsTnT: plasma high-sensitivity troponin T; NT-proBNP: N-terminal pro-brain natriuretic peptide; $\mathrm{Hb}$ : haemoglobin; CRP: C-reactive protein; PFT: pulmonary function test; FVC: forced vital capacity; FEV $_{1}$ : forced expiratory volume in $1 \mathrm{~s}$; TLC: total lung capacity; $D_{\text {Lco }}$ : diffusing capacity of the lung for carbon monoxide; $V_{A}$ : alveolar volume; mMRC: modified Medical Research Council; WHO: World Health Organization.

descriptives of the study. The age variation was from 18 to 88 years (table 1). Obesity (body mass index (BMI) $>30 \mathrm{~kg} \cdot \mathrm{m}^{-2}$ ) was found in 46 participants (30\%). Pulmonary embolus or deep vein thrombus related to the current hospitalisation was observed in 5\%. The participants were hospitalised for a median (IQR) of 6 (3-11) days. A total of 31 participants (20\%) were treated at an ICU for a median (IQR) of 9 (4-14) days, and 20 (13\%) were intubated and mechanically ventilated for a median (IQR) of 9 (7-15) days. At the time of the study, 3 months after hospital discharge, results below the lower limit of normal (z-score $\leqslant 1.64)$ were observed in $13 \%(n=19)$ for $\mathrm{FEV}_{1}, 5 \%(n=7)$ for forced vital 
capacity, $20 \%(\mathrm{n}=31)$ for $D_{\mathrm{LCO}}$ and $6 \%(\mathrm{n}=9)$ for $D_{\mathrm{LCO}} /$ alveolar volume. Dyspnoea, as indicated by mMRC 1-4, was reported in 59 participants (47\%) (table 1).

\section{Cardiopulmonary function}

$V^{\prime}{ }_{\mathrm{O}_{2} \text { peak }}<80 \%$ predicted was observed in 49 participants (31\%). $V_{\mathrm{O}_{2} \text { peak }}^{\prime} \cdot \mathrm{kg}^{-1}<80 \%$ predicted was observed in 73 participants (47\%). Pathological anaerobic threshold, $<40 \%$ predicted $V_{\mathrm{O}_{2} \max }^{\prime}$, was observed in 23 participants (15\%).

Ventilatory limitation was observed in 25 participants (16\%), expressed as breathing reserve <15\% [16, 19].

Mean \pm SD $S_{\mathrm{pO}_{2}}$ at rest was $98 \pm 1 \%$ and at maximal load was $95 \pm 4 \%$. We found a desaturation of $>5 \%$ points in $S_{\mathrm{pO}_{2}}$ between rest and maximal load in 34 participants (23\%).

Oxygen pulse $<80 \%$ predicted was observed in 28 participants $(18 \%)$. Of these, four demonstrated a declining oxygen pulse curve with increasing load. During exercise, a pathological response on ECG was observed in 12 participants (8\%). Of these, ischaemia and arrhythmia (mainly multifocal premature ventricular contractions) were found in seven and five participants, respectively.

Reduced ventilatory efficiency was observed in $15 \%(\mathrm{n}=24)$, defined by high $V_{\mathrm{E}}^{\prime} / V^{\prime} \mathrm{CO}_{2}$ slope and/or $V_{\mathrm{E}}^{\prime} /$ $V^{\prime} \mathrm{CO}_{2}$ nadir (z-score >1.96). A high $V_{\mathrm{E}}^{\prime} / V^{\prime} \mathrm{CO}_{2}$ slope was observed in $19(12 \%)$ and a high $V_{\mathrm{E}}^{\prime} / V^{\prime} \mathrm{CO}_{2}$ nadir in $16(10 \%)$. Among those with reduced ventilatory efficiency, four participants (17\%) had a ventilatory limitation, nine (38\%) had a circulatory limitation and 11 (46\%) had dysfunctional breathing patterns (hyperventilation, stress reaction). Among the nine participants with reduced ventilatory efficiency due to circulatory factors, seven demonstrated ECG pathology during exercise and two experienced venous thromboembolism during the acute phase of COVID-19.

TABLE 2 Comparison of cardiopulmonary exercise test variables in COVID-19 patients with the reference population

\begin{tabular}{|c|c|c|c|c|}
\hline & $\mathrm{n}$ & Mean \pm SD & Mean z-score & p-value \\
\hline \multicolumn{5}{|l|}{ Performance } \\
\hline$V^{\prime} \mathrm{O}_{2}$ peak, $\mathrm{mL} \cdot \mathrm{min}^{-1}$ & 156 & $2420 \pm 754$ & -0.62 & $<0.001$ \\
\hline$V_{\mathrm{O}_{2} \text { peak, }}^{\prime} \%$ pred & 156 & $89 \pm 17$ & & \\
\hline$V_{\mathrm{O}_{2} \text { peak }}^{\prime} \cdot \mathrm{kg}^{-1}, \mathrm{~mL} \cdot \mathrm{kg}^{-1} \cdot \mathrm{min}^{-1}$ & 156 & $28.7 \pm 8.4$ & -0.88 & $<0.001$ \\
\hline$V_{\mathrm{O}_{2} \text { peak }}^{\prime} \cdot \mathrm{kg}^{-1}, \%$ pred & 156 & $84 \pm 19$ & & \\
\hline Perceived dyspnoea (Borg CR10) at maximum load & 152 & $8.2 \pm 2.0$ & & \\
\hline \multicolumn{5}{|l|}{ Ventilation } \\
\hline$V_{E}^{\prime}$ at maximum load, L.min ${ }^{-1}$ & 156 & $85.1 \pm 28.6$ & -0.65 & $<0.001$ \\
\hline Breathing reserve, $\%$ & 156 & $30 \pm 17$ & 0.27 & 0.016 \\
\hline \multicolumn{5}{|l|}{ Circulation } \\
\hline $\mathrm{HR}$ at maximum load, beats $\cdot \mathrm{min}^{-1}$ & 156 & $157 \pm 20$ & -1.14 & $<0.001$ \\
\hline HR at maximum load, \% pred & 156 & $92 \pm 10$ & & \\
\hline Systolic BP at maximum load, $\mathrm{mmHg}$ & 147 & $193 \pm 34$ & 0.20 & 0.048 \\
\hline Diastolic BP at maximum load, $\mathrm{mmHg}$ & 147 & $84 \pm 19$ & 0.28 & 0.008 \\
\hline Oxygen pulse at maximum load, $\mathrm{mL} \cdot$ stroke $^{-1}$ & 156 & $15.4 \pm 4.2$ & -0.09 & 0.13 \\
\hline Oxygen pulse at maximum load, \% pred & 156 & $98 \pm 19$ & & \\
\hline \multicolumn{5}{|l|}{ Gas exchange } \\
\hline$V_{\mathrm{E}}^{\prime} / V_{\mathrm{CO}_{2}}^{\prime}$ slope & 156 & $28.0 \pm 4.5$ & 0.40 & 0.001 \\
\hline$V^{\prime}{ }_{E} / V^{\prime} \mathrm{CO}_{2}$ nadir & 156 & $28.5 \pm 3.7$ & 0.30 & 0.001 \\
\hline RER at maximum load & 155 & $1.07 \pm 0.10$ & -1.04 & $<0.001$ \\
\hline$P_{\mathrm{ETCO}_{2}}$ at AT, $\mathrm{kPa}$ & 155 & $4.7 \pm 0.6$ & & \\
\hline$P_{\mathrm{CO}_{2}}$ at maximum load, $\mathrm{kPa}$ & 143 & $4.6 \pm 0.6$ & & \\
\hline \multicolumn{5}{|l|}{ Anaerobic threshold } \\
\hline$V^{\prime} \mathrm{O}_{2}$ at $\mathrm{AT}, \mathrm{mL} \cdot \mathrm{min}^{-1}$ (V-slope) & 152 & $1387 \pm 417$ & & \\
\hline$V_{\mathrm{O}_{2}}^{\prime}$ at $\mathrm{AT}, \%$ pred $V_{\mathrm{O}_{2} \max }^{\prime}$ & 152 & $52 \pm 12$ & & \\
\hline Lactate at maximum load, $\mathrm{mmol} \cdot \mathrm{L}^{-1}$ & 140 & $9.0 \pm 3.5$ & -0.1 & 0.22 \\
\hline
\end{tabular}


TABLE 3 Comparison of cardiopulmonary exercise test variables according to self-reported dyspnoea

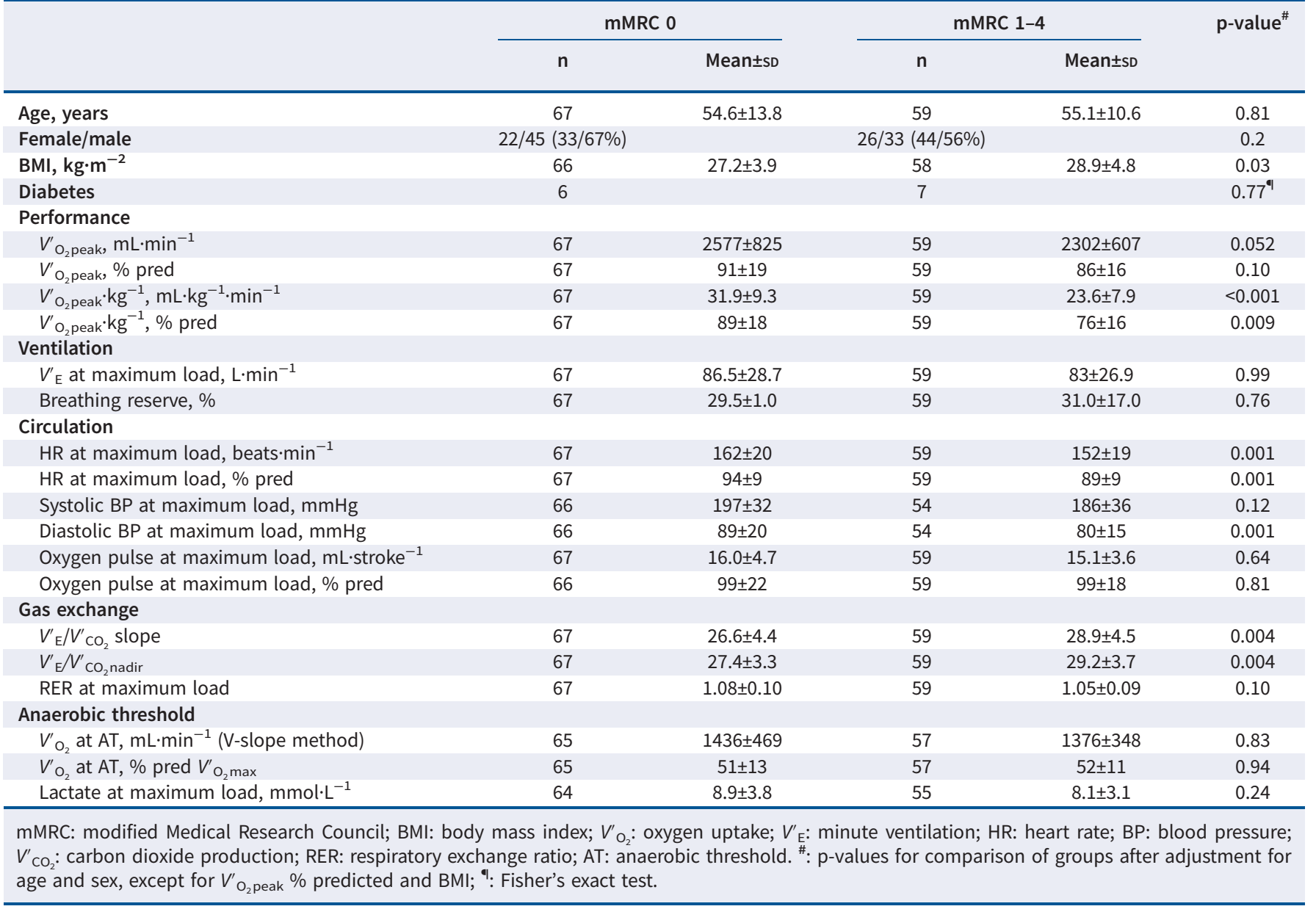

Exercise limiting factors were multifactorial and described in the 49 participants with $V_{\mathrm{O}_{2} \text { peak }}<80 \%$ predicted. Ventilatory limitations were observed in seven (14\%), circulatory limitations in 11 (22\%) and deconditioning in 31 (63\%).

Table 2 summarises the differences of the CPET variables in the COVID-19 patients compared with the reference population.

\section{Cardiopulmonary function in subgroups \\ Dyspnoea}

The participants reporting dyspnoea had significantly lower $V^{\prime}{ }_{\mathrm{O}_{2} \text { peak }} \cdot \mathrm{kg}^{-1}$, ventilatory efficiency, heart rate and systolic blood pressure (table 3). The low $V^{\prime}{ }_{\mathrm{O}_{2} \text { peak }} \cdot \mathrm{kg}^{-1}$ in the dyspnoeic group was related to higher BMI, as $V_{\mathrm{O}_{2} \text { peak }}^{\prime}$ was similar between the groups $(\mathrm{p}=0.052)$.

ICU stay

The participants with ICU stay had significantly lower $V_{\mathrm{O}_{2} \text { peak }}^{\prime} \%$ predicted $(90 \pm 17 \%$ versus $82 \pm 15 \%$; $\mathrm{p}=0.004)$ and $V_{\mathrm{O}_{2} \text { peak }}^{\prime} \cdot \mathrm{kg}^{-1} \%$ predicted (86 $\pm 19 \%$ versus $76 \pm 15 \%$; $\left.\mathrm{p}=0.002\right)$ compared with those without ICU stay. No difference was found regarding age, BMI, ventilation, breathing reserve, oxygen desaturation, ventilatory efficiency or oxygen pulse.

\section{Discussion}

The current study demonstrated $V^{\prime}{ }_{\mathrm{O}_{2} \text { peak }}<80 \%$ predicted in one-third of COVID-19 patients 3 months after hospital discharge. Every sixth participant had a reduced breathing reserve, ventilatory efficiency, oxygen pulse or a combination. Deconditioning was the major cause of exercise limitation, followed by circulatory 
and ventilatory exercise limitation. Self-reported dyspnoea was associated with lower ventilatory efficiency and lower $V_{\mathrm{O}_{2} \text { peak }}^{\prime} \mathrm{kg}^{-1}$ due to higher BMI. There was less difference in cardiorespiratory exercise response than expected between participants admitted to the ICU or regular hospital ward.

Reduced exercise capacity is an independent predictor of death in men [20] and women [21]. Our finding of low $V_{\mathrm{O}_{2} \text { peak }}^{\prime}$ compared with a reference population therefore emphasises the importance of regaining exercise capacity after COVID-19. BeLLi et al. [22] reported difficulty regaining physical ability after COVID-19, which has led to a recommendation of rehabilitation programmes [22]. We observed that $V^{\prime} \mathrm{O}_{2}$ peak $\mathrm{kg}^{-1}$ was more divergent from the reference population than $V_{\mathrm{O}_{2} \text { peak }}^{\prime}$, reflecting obesity in our study population. Obesity is a well-recognised risk factor for severe COVID-19 [23].

Two studies including COVID-19 patients found $V^{\prime}{ }_{\mathrm{O}_{2} \text { peak }} 81 \%$ and $73 \%$ predicted [3, 24], which is comparable to our results, whereas another study reported $V^{\prime}{ }_{\mathrm{O}_{2} \text { peak }} 57 \%$ predicted for mechanically ventilated COVID-19 patients [12].

Exercise limiting factors can be related to ventilation, circulation, deconditioning or peripheral mechanisms. Deconditioning was the leading cause of exercise limitation in the present study and found in every fifth participant. Immobilisation during hospitalisation for 10 days combined with further inactivity due to exertional dyspnoea could be the reason for the deconditioning in our participants, where reduced cardiac output, peripheral limiting factors and muscle waste contribute. In a recent report of 18 COVID-19 patients at the time of discharge from hospital, peripheral limiting factors, including anaemia and reduced oxygen extraction by peripheral muscles, were the major determinants of exercise limitation [25]. However, our study population did not suffer from anaemia during the hospital stay or at follow-up.

The second most common cause of exercise limitation was circulatory factors. COVID-19 might affect multiple organs, including the heart and blood vessels [26]. The finding of frequent circulatory exercise limitation could rely on factors other than post-COVID sequelae. Even though we excluded participants with known pre-existing cardiovascular disease, some might still have had undiagnosed pre-existing cardiovascular conditions that were revealed during the CPET. Furthermore, the diagnostic accuracy of an exercise ECG is 70\% [27] and we cannot rule out deconditioning as the true exercise limitation for some of these participants. Two participants with circulatory exercise limitation experienced pulmonary embolism during hospitalisation, but it is unlikely that this contributed to circulatory exercise limitation 3 months after discharge. A haemodynamic study of 21 mechanically ventilated COVID-19 patients, including three with pulmonary embolus, found normal pulmonary vascular resistance for all. Post-capillary pulmonary hypertension was present in $76 \%$, but none exhibited the pre-capillary form related to pulmonary embolisation [28].

Ventilatory limitation was the third most common cause of exercise limitation. We have recently reported pulmonary parenchymal abnormalities by chest computed tomography in $25 \%$ of a sample from the same population [7]. However, low breathing reserve was not common among our participants, showing that breathing reserve may be within normal limits, even in the presence of parenchymal abnormalities. Few participants had reduced spirometry and gas diffusion capacity, as well as reduced breathing reserve during exercise, in contrast to what was anticipated for this population at the beginning of the pandemic. The discordance in results of pulmonary function tests and the lower exercise capacity supports the finding of a low occurrence of ventilatory limitation, as deconditioning represents the major limitation of the study population. Deconditioning is a positive finding in the context of regaining physical function through rehabilitation.

Ventilatory efficiency was reduced in every seventh patient. There was evidence of ventilation/perfusion $\left(V^{\prime} / Q^{\prime}\right)$ mismatch due to pulmonary or circulatory factors in about half of these patients. For the other half, a dysfunctional breathing pattern seemed to contribute to the reduced ventilatory efficiency. Unfortunately, we did not have arterial blood gas analyses to prove hyperventilation. However, a dysfunctional breathing pattern and hyperventilation has been reported as a frequent cause of dyspnoea in a study of mild COVID-19 survivors [29]. Whether this is related to dysautonomia or other factors is unclear.

As comorbidity affects exercise capacity, we excluded participants with severe comorbidities. In contrast, we did not exclude participants with well-regulated diabetes mellitus or hypertension, as the reference population for the CPETs also included such participants [18]. Asthma was common in the study population, but asthma sufferers did not exhibit ventilatory limitation and well-controlled asthma should not interfere with exercise capacity. 


\section{Cardiopulmonary function in subgroups}

Exertional dyspnoea was frequently reported among our participants, which is in line with other studies [4-8]. Dyspnoea is a complex symptom that has been defined by the American Thoracic Society as the net result of multiple physiological, psychological, social and environmental factors [30].

When we compared participants with and without dyspnoea, the dyspnoeic participants had significantly

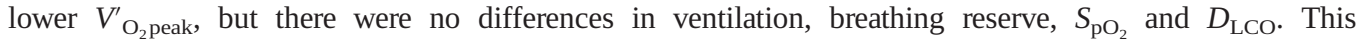
indicates that dyspnoea is associated with factors other than pulmonary function.

$V^{\prime}{ }_{E} / V^{\prime} \mathrm{CO}_{2}$ slope and $V_{E}^{\prime} / V^{\prime} \mathrm{CO}_{2}$ nadir were higher in the dyspnoeic group. These high values mainly reflect $V^{\prime} / Q^{\prime}$ mismatch, but might also represent dysfunctional breathing. Deconditioning alone could not explain the difference in perception of dyspnoea, as $V^{\prime} \mathrm{O}_{2}$ at anaerobic threshold values, both absolute and relative to predicted $V^{\prime} \mathrm{O}_{2}$ max , were similar and low in both groups. Hence, our results indicate that dyspnoea after COVID-19 is complex with several explanations.

The participants admitted to the ICU had more severe oxygenation problems in the acute phase and three times longer hospital stay than those not admitted to the ICU. At 3 months after discharge, the ICU participants had significantly lower $V_{\mathrm{O}_{2}}^{\prime}$ peak. Otherwise, they had similar test results. We had expected ICU participants to have more ventilatory limitations, worse oxygen desaturation, more $V^{\prime} / Q^{\prime}$ mismatch and earlier anaerobic threshold due to deconditioning. To the best of our knowledge, there are no CPET studies on COVID-19 patients treated in the ICU versus regular ward for comparison with our findings. The results observed for the ICU participants might be due to extra care after discharge, with higher attendance at inpatient rehabilitation programmes than non-ICU participants. Results probably also reflect the effect of substantial lung tissue repair during the first 3 months [31, 32].

\section{Limitations and strengths}

We did not have objective measures for prior functional status and exercise capacity for the study population. We have compared the participants with a healthy reference population, although we have documented pre-existing comorbidities. Estimates of oxygen saturation during exercise using pulse oximetry should be viewed cautiously, as errors might have occurred. CPET generates numerous variables, with the risk of errors due to multiple testing. The limited number of participants in the ICU group could possibly lead to type 2 errors. The study's strength is its design, with an unselected hospital population and extensive medical examination of the participants. Even though fewer patients were treated in the ICU compared with many other countries, the proportion of comorbidities and obesity is comparable to other studies, and we consider our study and the results generalisable to other countries.

\section{Conclusions}

At 3 months after discharge from hospital after COVID-19, $V_{\mathrm{O}_{2}}^{\prime}$ peak was reduced in one-third of participants. The most common exercise limitation was deconditioning, emphasising the importance of rehabilitation programmes. Circulatory limitations to exercise were more common than ventilatory limitations. Participants with self-reported dyspnoea had lower $V_{\mathrm{O}_{2} \text { peak }}^{\prime} \mathrm{kg}^{-1}$ and ventilatory efficiency. There were no differences in ventilation or ventilatory efficiency between those with or without ICU admission. In patients with persisting exercise limitations and dyspnoea after COVID-19, a CPET is essential for identifying the causes.

This study was registered at ClinicalTrials.gov with identifier number NCT04535154.

Conflict of interest: I. Skjørten has provided lectures for doctors' education paid by Norwegian Directorate of Health and Norwegian Medical Association. O.A.W. Ankerstjerne has nothing to disclose. D. Trebinjac has nothing to disclose. E. Brønstad has nothing to disclose. Ø. Rasch-Halvorsen has nothing to disclose. G. Einvik has received research grants from AstraZeneca and from Boehringer Ingelheim to perform the current study. T.V. Lerum has nothing to disclose. K. Stavem has nothing to disclose. A. Edvardsen is leader of the Norwegian Society for Clinical Physiology (unpaid), and has received payment or honoraria for lectures, presentations, speakers bureaus, manuscript writing or educational events from GlaxoSmithKline and Chiesi. C.B. Ingul has received lecture fees from Bayer AS, unrelated to the current study.

Support statement: This work was supported by the Landsforeningen for Hjerte- og Lungesyke, Akershus Universitetssykehus and Nasjonalforeningen for Folkehelsen. 
References

1 Zhou P, Yang XL, Wang XG, et al. A pneumonia outbreak associated with a new coronavirus of probable bat origin. Nature 2020; 579: 270-273.

2 Wiersinga WJ, Rhodes A, Cheng AC, et al. Pathophysiology, transmission, diagnosis, and treatment of coronavirus disease 2019 (COVID-19): a review. JAMA 2020; 324: 782-793.

3 Raman B, Cassar MP, Tunnicliffe EM, et al. Medium-term effects of SARS-CoV-2 infection on multiple vital organs, exercise capacity, cognition, quality of life and mental health, post-hospital discharge. EClinicalMedicine 2021; 31: 100683.

4 Huang C, Huang L, Wang Y, et al. 6-month consequences of COVID-19 in patients discharged from hospital: a cohort study. Lancet 2021; 397: 220-232.

5 Carfi A, Bernabei R, Landi F, et al. Persistent symptoms in patients after acute COVID-19. JAMA 2020; 324: 603-605.

6 Goertz YMJ, Van Herck M, Delbressine JM, et al. Persistent symptoms 3 months after a SARS-CoV-2 infection: the post-COVID-19 syndrome? ERJ Open Res 2020; 6: 00542-2020.

7 Lerum TV, Aalokken TM, Bronstad E, et al. Dyspnoea, lung function and CT findings 3 months after hospital admission for COVID-19. Eur Respir J 2021; 57: 2003448.

8 Stavem K, Ghanima W, Olsen MK, et al. Persistent symptoms 1.5-6 months after COVID-19 in non-hospitalised subjects: a population-based cohort study. Thorax 2021; 76: 405-407.

9 Fletcher CM, Elmes PC, Fairbairn AS, et al. The significance of respiratory symptoms and the diagnosis of chronic bronchitis in a working population. Br Med J 1959; 2: 257-266.

10 Radtke T, Crook S, Kaltsakas G, et al. ERS statement on standardisation of cardiopulmonary exercise testing in chronic lung diseases. Eur Respir Rev 2019; 28: 180101.

11 Corra U, Agostoni PG, Anker SD, et al. Role of cardiopulmonary exercise testing in clinical stratification in heart failure. A position paper from the Committee on Exercise Physiology and Training of the Heart Failure Association of the European Society of Cardiology. Eur J Heart Fail 2018; 20: 3-15.

12 Blokland IJ, Ilbrink S, Houdijk H, et al. Exercise capacity after mechanical ventilation because of COVID-19: cardiopulmonary exercise tests in clinical rehabilitation. Ned Tijdschr Geneeskd 2020; 164: D5253.

13 World Health Organization. R\&D Blueprint: novel Coronavirus. COVID-19 Therapeutic Trial Synopsis. 2020. www.who.int/blueprint/priority-diseases/key-action/COVID-19_Treatment_Trial_Design_Master_Protocol_synopsis_ Final_18022020.pdf Date last accessed: 3 July 2021.

14 Quanjer PH, Stanojevic S, Cole TJ, et al. Multi-ethnic reference values for spirometry for the 3-95-year age range: the global lung function 2012 equations. Eur Respir J 2012; 40: 1324-1343.

15 Stanojevic S, Graham BL, Cooper BG, et al. Official ERS technical standards: Global Lung Function Initiative reference values for the carbon monoxide transfer factor for Caucasians. Eur Respir J 2017; 50: 1700010.

16 Sietsema KE, Sue DY, Stringer WW, et al. Wasserman \& Whipp's Principles of Exercise Testing and Interpretation. 6 Edn. Dordrecht, Wolters Kluwer, 2021.

17 Borg GA. Psychophysical bases of perceived exertion. Med Sci Sports Exerc 1982; 14: 377-381.

18 Edvardsen E, Hansen BH, Holme IM, et al. Reference values for cardiorespiratory response and fitness on the treadmill in a 20- to 85-year-old population. Chest 2013; 144: 241-248.

19 Takken T, Mylius CF, Paap D, et al. Reference values for cardiopulmonary exercise testing in healthy subjects - an updated systematic review. Expert Rev Cardiovasc Ther 2019; 17: 413-426.

20 Myers J, Prakash M, Froelicher V, et al. Exercise capacity and mortality among men referred for exercise testing. N Engl J Med 2002; 346: 793-801.

21 Gulati M, Black HR, Shaw LJ, et al. The prognostic value of a nomogram for exercise capacity in women. N Engl J Med 2005; 353: 468-475.

22 Belli S, Balbi B, Prince I, et al. Low physical functioning and impaired performance of activities of daily life in COVID-19 patients who survived hospitalisation. Eur Respir J 2020; 56: 2002096.

23 Sattar N, McInnes IB, McMurray JJV. Obesity is a risk factor for severe COVID-19 infection: multiple potential mechanisms. Circulation 2020; 142: 4-6.

24 Mohr A, Dannerbeck L, Lange TJ, et al. Cardiopulmonary exercise pattern in patients with persistent dyspnoea after recovery from COVID-19. Multidiscip Respir Med 2021; 16: 732.

25 Baratto C, Caravita S, Faini A, et al. Impact of COVID-19 on exercise pathophysiology. A combined cardiopulmonary and echocardiographic exercise study. J Appl Physiol 2021; 30: 1470-1478.

26 Giustino G, Pinney SP, Lala A, et al. Coronavirus and cardiovascular disease, myocardial injury, and arrhythmia: JACC Focus Seminar. J Am Coll Cardiol 2020; 76: 2011-2023.

27 Bourque JM, Beller GA. Value of exercise ECG for risk stratification in suspected or known CAD in the era of advanced imaging technologies. JACC Cardiovasc Imaging 2015; 8: 1309-1321.

28 Caravita S, Baratto C, Di Marco F, et al. Haemodynamic characteristics of COVID-19 patients with acute respiratory distress syndrome requiring mechanical ventilation. An invasive assessment using right heart catheterization. Eur J Heart Fail 2020; 22: 2228-2237. 
29 Motiejunaite J, Balagny P, Arnoult F, et al. Hyperventilation: a possible explanation for long-lasting exercise intolerance in mild COVID-19 survivors? Front Physiol 2020; 11: 614590.

30 Parshall MB, Schwartzstein RM, Adams L, et al. An official American Thoracic Society statement: update on the mechanisms, assessment, and management of dyspnea. Am J Respir Crit Care Med 2012; 185: 435-4452.

31 Liang L, Yang B, Jiang N, et al. Three-month follow-up study of survivors of coronavirus disease 2019 after discharge. J Korean Med Sci 2020; 35: e418.

32 Liu M, Lv F, Huang Y, et al. Follow-up study of the chest CT characteristics of COVID-19 survivors 7 months after recovery. Front Med 2021; 8: 636298. 